\title{
Occupational exposure to particulate air pollution and mortality due to ischaemic heart disease and cerebrovascular disease
}

\author{
Kjell Torén, Ingvar A Bergdahl, Tohr Nilsson, Bengt Järvholm
}

Occup Environ Med 2007;64:515-519. doi: 10.1136/oem.2006.029488

See end of article for authors' affiliations

Correspondence to

Professor K Torén,

Department of Occupational and Environmental

Medicine, Sahlgrenska

University Hospital, Box

414, S-405 30 Göteborg,

Sweden; Kjell.Toren@amm. gu.se

Accepted 12 January 2007 Published Online First 15 February 2007 miological studies are showing that ambient exposure to particulate Objectives: A growing number of epidemiological studies are showing that ambient exposure to particulate
matter air pollution is a risk factor for cardiovascular disease; however, whether occupational exposure increases this risk is not clear. The aim of the present study was to examine whether occupational exposure to particulate air pollution increases the risk for ischaemic heart disease and cerebrovascular disease.

Methods: The study population was a cohort of 176309 occupationally exposed Swedish male construction workers and 71778 unexposed male construction workers. The definition of exposure to inorganic dust (asbestos, man-made mineral fibres, dust from cement, concrete and quartz), wood dust, fumes (metal fumes, asphalt fumes and diesel exhaust) and gases and irritants (organic solvents and reactive chemicals) was based on a job-exposure matrix with focus on exposure in the mid-1970s. The cohort was followed from 1971 to 2002 with regard to mortality to ischaemic heart disease and cerebrovascular disease. Relative risks (RR) were obtained by the person-years method and from Poisson regression models adjusting for baseline values of blood pressure, body mass index, age and smoking habits.

Results: Any occupational particulate air pollution was associated with an increased risk for ischemic heart disease (RR 1.13,95\% Cl 1.07 to 1.19), but there was no increased risk for cerebrovascular disease (RR $0.97,95 \% \mathrm{Cl} 0.88$ to 1.07$)$. There was an increased risk for ischaemic heart disease and exposure to inorganic dust (RR 1.07, 95\% Cl 1.03 to 1.12) and exposure to fumes (RR $1.05,95 \% \mathrm{Cl} 1.00$ to 1.10 ), especially diesel exhaust (RR $1.18,95 \% \mathrm{Cl} 1.13$ to 1.24). There was no significantly increased risk for cerebrovascular disease and exposure to inorganic dust, fumes or wood dust.

Conclusions: Occupational exposure to particulate air pollution, especially diesel exhaust, among construction workers increases the risk for ischaemic heart disease.
$\mathrm{T}$ here are a growing number of epidemiological studies showing that ambient exposure to particulate matter air pollution is a risk factor for cardiovascular disease. ${ }^{1-6}$ However, regarding the risk for cerebrovascular disease and exposure to air pollution the literature is more scanty, and recent studies have shown conflicting results. ${ }^{7-9}$ Occupationally exposed groups often have high exposure to particulate air pollution, such as silica dust, asbestos or welding fumes, but whether such dust exposure increases the risk for ischaemic heart disease or cerebrovascular disease is not clear.

Our understanding of the underlying pathogenetic mechanisms remains limited, but it has been proposed that inhalation of small particles induces an inflammatory reaction in the airways and subsequent induction of systemic inflammation and coagulation disturbances. ${ }^{10} 11$

There is also increasing evidence of an association between ambient particulate air pollution and disturbances of the cardiac autonomic nervous system. Several groups have reported changes in heart rate variability associated with ambient particulate air pollution. ${ }^{12-15}$ It has also been shown that acute exposure to particulate air pollution increases the risk of ST-segment depression among subjects with coronary heart disease and also increases the discharges from pacemakers. ${ }^{1617}$

A major methodological problem regarding epidemiological studies on occupationally exposed groups and the risk for cardiovascular diseases is healthy worker selection bias. Exposed cohorts are often compared with national populations, causing an underestimation of the "true" risk, because the general population includes sick and disabled people who are at increased risk of coronary heart disease. For the same reason, most cohort studies of workers who are occupationally exposed to particulate air pollution have also shown a decreased risk for ischaemic heart disease, as they often are compared with general populations. There are some exceptions, ${ }^{18-21}$ but these studies do not make sufficient adjustments for confounders such as smoking, hypertension, sex and body mass index (BMI). However, there is a large case-referent study with proper adjustments for confounders showing an increased risk for myocardial infarction among those occupationally exposed to combustion products. ${ }^{22}$

Consequently, to establish the effect of occupational exposure to particulate air pollution and risk for cardiovascular disease there is a need for a large cohort study which, in addition to exposure information, also includes information about relevant confounders. In the following, we report the results of a prospective cohort study of 176309 Swedish male construction workers exposed to inorganic dust, wood dust, fumes and gases and 71778 unexposed Swedish construction workers. The specific aim of the study was to elucidate whether occupational exposure to dust, fumes and gases increases the risk for death from cardiovascular disease-that is, ischaemic heart disease and cerebrovascular disease.

\section{METHODS}

The Swedish Construction Industry's Organization for Working Environment, Occupational Health and Safety ("Bygghälsan")

Abbreviations: $B M I$, body mass index; ICD, International Classification of Diseases; JEM, job exposure matrix 
Table 1 Basic data on a cohort of 248087 Swedish male construction workers

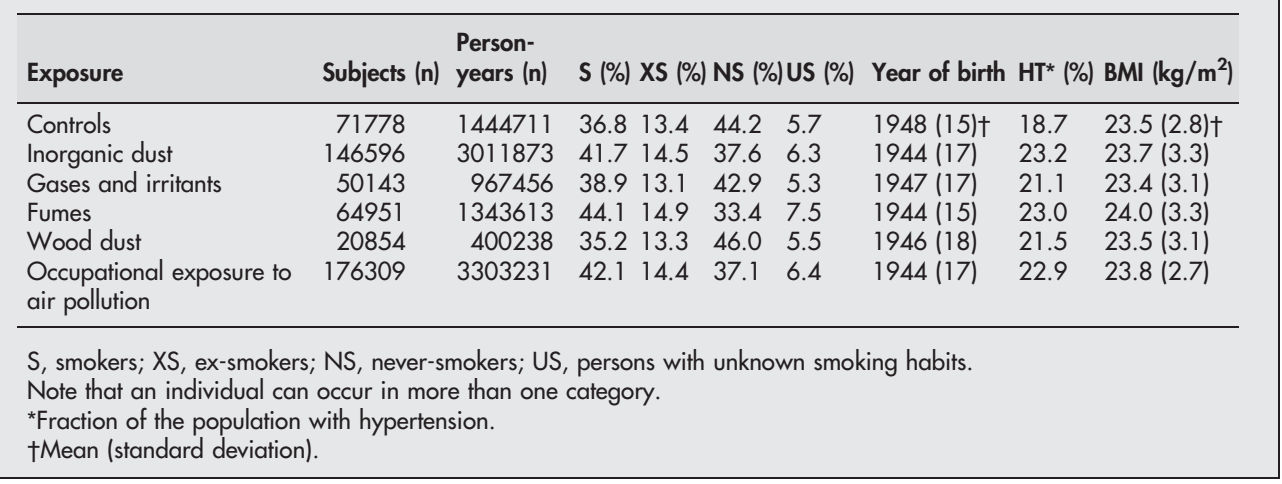

was established in 1968 to coordinate all activities concerning occupational health among Swedish construction workers. Construction workers were invited to medical examinations at intervals of 2-5 years. Although the programme was voluntary, at least $80 \%$ of eligible workers participated at least once. Data from the health examinations, including occupational titles, smoking habits, blood pressure, height and weight were registered in a central database established in the early 1970s, as previously described. ${ }^{23}{ }^{24}$ The database includes records of medical examinations performed during the period 1971-93.

Through the personal identity number and a linkage with the National Cause of Death Register it was possible to identify subjects who had died (underlying cause) from ischaemic heart disease or cerebrovascular disease. We used the diagnoses from the International Classification of Diseases (ICD), categories 410-412 (ICD, 9th revision (ICD-9)) and I2 l-I25 (ICD 10) for ischaemic heart disease and categories 430-438 (ICD 9) and I60-I69 (ICD 10) for cerebrovascular disease.

Each worker was followed from entry into the cohort (earliest entry l January 1971) until 31 December 2001. The loss of subjects was low $(0.15 \%)$ and mainly due to emigration. Such persons were excluded from the analysis. Those examined at baseline before the age of 15 or after the age of 67 years were likewise excluded.

Smoking habits were categorised according to information from the first health examination. If information on smoking was lacking in the records of the first examination, we used information from a later visit. In a small proportion of subjects smoking habit was unknown. These subjects were treated as a separate group in the analysis. Based on smoking habits at baseline, subjects were consequently classified as "neversmokers", "ex-smokers", "current smokers" or "persons with unknown smoking habits".

Blood pressure was measured at baseline and hypertension was defined as either systolic blood pressure of $140 \mathrm{~mm} \mathrm{Hg}$ or higher or diastolic blood pressure of $90 \mathrm{~mm} \mathrm{Hg}$ or higher. BMI was calculated for all subjects as [weight $(\mathrm{kg}) /$ height $\left.^{2}(\mathrm{~m})\right]$. Subjects lacking information about height, weight or blood pressure were excluded (about $7 \%$ in all strata).

The occupational title at the time of the first health examination was used. Most workers remained in the same occupation throughout the study period. Among the workers who participated in repeated examinations, $74 \%$ reported the same occupation. A job exposure matrix (JEM) was developed for selected exposures, as previously described. ${ }^{24}$ The JEM was based on exposure estimations from the 1970s, where each occupation was studied at visits to approximately five different sites in different geographical regions of Sweden. The estimations in the 1970s were performed by industrial hygienists. Exposures to asbestos, asphalt fumes, cement dust, concrete dust, diesel exhaust, epoxy resins, isocyanates, man-made mineral fibres, metal fumes, organic solvents, quartz dust and wood dust were assessed, with focus on exposure during the mid-1970s. Each factor was initially graded on a 0-5 scale, but finally divided into two groups, "exposed" or "not exposed", where "not exposed" where those graded as zero, and "exposed" were those graded 0.5 to 5. Common occupations among the "not exposed" were certain carpenters, roofers, reinforcement workers, crane operators and supervisors.

For the purpose of this study, the specific exposures were further merged into four broader exposure categories, namely exposure to inorganic dust (asbestos, cement dust, concrete dust, man-made mineral fibres, or quartz), gases and irritants (organic solvents, epoxy resins, or diisocyanates), fumes (metal fumes, asphalt fumes or diesel exhaust) and wood dust, respectively. There is an overlap between the four major exposure groups. In particular, workers classified as exposed to inorganic dust were also exposed to gases and irritants, and also to fumes. An additional separate analysis was performed with fumes divided into metal fumes, asphalt fumes and diesel exhaust.

After exclusions due to missing data (BMI and blood pressure), the exposed group consisted of 176309 men. In the job-exposure matrix 116894 men were assessed as not exposed. After exclusions due to missing data, the group consisted of 110656 men. Among them, there were 38878 white-collar workers (office workers), who for the purpose of this study were excluded resulting in a control group of 71 778 men. Consequently, the study was performed on 176309 exposed workers and 71778 controls (table 1). The study was approved by the Committee of Ethics at Umeå University.

\section{Statistics}

Relative risks (RR) were calculated with the person-year method $^{25}$ using the age distribution in the reference group as control. Person-years were calculated from the calendar year after the first health examination, until death, emigration, or to 31 December 2001 whichever came first. The analyses were stratified according into 135 -year age groups, into four groups according to smoking habits, BMI (15-19, 20-25 and 25-30 kg/ $\mathrm{m}^{2}$ ), and into two groups with regard to hypertension (yes/no). Person-years generated after 84 years and before 20 years were excluded. Ninety five per cent confidence intervals (CIs) were calculated using a Poisson distribution.

The influence of the different exposures-smoking, hypertension, BMI and age-was analysed in Poisson regression models, ${ }^{26}$ with mortality from ischaemic heart disease and cerebrovascular disease, respectively, as the dependent variable. Exposure was either handled as "any exposure" or separated into four different exposures (inorganic dust, gases and irritants, fumes and wood dust). 
Table 2 Mortality from ischaemic heart disease and cerebrovascular disease

\begin{tabular}{|c|c|c|c|c|}
\hline \multirow[b]{2}{*}{ Exposure } & \multicolumn{2}{|c|}{ Ischaemic heart disease } & \multicolumn{2}{|c|}{ Cerebrovascular diseases } \\
\hline & $n$ & RR $(95 \% \mathrm{Cl})$ & $n$ & RR $(95 \% \mathrm{Cl})$ \\
\hline Contr & & & 496 & \\
\hline $\begin{array}{l}\text { Occupational } \\
\text { exposure to } \\
\text { particulate air } \\
\text { pollution }\end{array}$ & & & & \\
\hline$=d u$ & & & 1552 & \\
\hline Gas & 1771 & & 467 & 0.9 \\
\hline & 2197 & & 616 & \\
\hline & 17 & 1. & 423 & 1.0 \\
\hline Asp & 171 & $1.12(\mathrm{C}$ & 45 & $1.18(0.86$ to 1.58$)$ \\
\hline & & & 205 & \\
\hline Wood du & 786 & $1.12(1.04$ to 1.20$)$ & 201 & 0.91 (0.79 to 1.04$)$ \\
\hline
\end{tabular}

Analysed with the person-years method adjusted for smoking, age, hypertension and body mass index.

\section{RESULTS}

There were 7273 deaths from ischemic heart disease and 1813 deaths from cerebrovascular disease among the exposed workers. There were 1790 and 497 deaths, respectively, among the controls. Using the person-year method, a stratified analysis weighing for smoking, age, BMI and hypertension showed an increased relative risk to die from ischemic heart disease (RR 1.12 , 95\% CI 1.07 to 1.18 ) among workers with occupational exposure to particulate air pollution (table 2). There were also increased risks in the different exposure categories. There was no increased mortality from cerebrovascular disease in any occupational exposure category.

A separate analysis of those exposed to fumes indicated an increased risk of ischemic heart disease for those exposed to diesel exhaust (RR 1.18, 95\% CI 1.13 to 1.24), while for those exposed to metal fumes (RR 1.01, 95\% CI 0.95 to 1.08 ) or to asphalt fumes (RR 1.12, 95\% CI 0.96 to 1.30) the risks were not significantly increased (table 2). There were no significantly increased risks for cerebrovascular disease when separately analysing exposure to diesel exhaust, metal fumes or asphalt fumes.

Among current smokers the relative risk was increased for ischemic heart disease (RR 1.15, 95\% CI 1.12 to 1.19 ), but not for cerebrovascular disease (RR 0.96 , 95\% CI 0.90 to 1.02 ), among those exposed to occupational particulate air pollution. Among exposed never-smokers there were slightly increased

Table 3 Poisson regression models. In addition to the listed predictors, the models were adjusted for age using 13 5 -year categories (20-84 years)

\begin{tabular}{|c|c|c|}
\hline \multirow[b]{2}{*}{ Predictor (exposure) } & \multicolumn{2}{|l|}{ Relative risk $(95 \% \mathrm{Cl})$} \\
\hline & $\begin{array}{l}\text { Ischaemic heart } \\
\text { diseaset }\end{array}$ & $\begin{array}{l}\text { Cerebrovascular } \\
\text { disease }\end{array}$ \\
\hline Inorganic dust ${ }^{\star}$ & 1.07 (1.03 to 1.12$)$ & 0.95 (0.87 to 1.04$)$ \\
\hline Gases and irritants* & 1.03 (0.97 to 1.09$)$ & 1.05 (0.94 to 1.17$)$ \\
\hline Fumes* & $1.05(1.00$ to 1.10$)$ & 1.09 (0.95 to 1.26$)$ \\
\hline Wood dust* & $1.01(0.93$ to 1.10$)$ & 0.86 (0.72 to 1.02$)$ \\
\hline Current smoking* & 1.61 (1.54 to 1.69$)$ & 1.35 (1.24 to 1.48 ) \\
\hline Ex-smoking* & $1.00(0.94$ to 1.06$)$ & 0.92 (0.82 to 1.04$)$ \\
\hline Body mass index $25-29.9^{*}$ & $1.25(1.20$ to 1.30$)$ & $1.16(1.07$ to 1.26$)$ \\
\hline Body mass index $15-19.9^{*}$ & $0.89(0.78$ to 1.02$)$ & 1.25 (1.00 to 1.57$)$ \\
\hline Hypertension* & 1.94 (1.86 to 2.03$)$ & 2.02 (1.86 to 2.20$)$ \\
\hline
\end{tabular}

*Binary outcome $(1=$ Yes, $0=\mathrm{No})$.

†Deviance of the model $=2425$, degrees of freedom $=3147$.

tDeviance of the model $=1494$, degrees of freedom $=3147$. risks with regard to ischaemic heart disease and cerebrovascular disease, but the confidence interval included unity.

When there were separate analyses stratified according to age, the relative risk for ischaemic heart disease in all exposure categories was higher among workers in occupationally active age (20-59 years) compared to ages above 59 years. For example, regarding occupational exposure to fumes the relative risk for men aged $20-59$ years was 1.28 (95\% CI 1.17 to 1.39$)$ as compared to 1.08 ( 1.03 to 1.13 ) among those men aged 60-84 years. There was no clear pattern according to age for cerebrovascular disease.

In a Poisson regression model the relative risk for ischaemic heart disease was clearly increased (RR 1.13, 95\% CI 1.07 to 1.19) among construction workers with occupational exposure to particulate air pollution, but there was no increased risk regarding cerebrovascular disease (RR $0.97,95 \%$ CI 0.88 to 1.07). Table 3 shows the results when analysing different exposures and confounders. The relative risks decreased in general, but remained higher for ischaemic heart disease among those exposed to inorganic dust (RR 1.07, 95\% CI 1.03 to 1.12 ) and fumes (RR $1.05,95 \%$ CI 1.00 to 1.10 ). There was also a tendency for an increased risk for cerebrovascular disease among workers exposed to fumes (RR 1.09, 95\% CI 0.95 to $1.26)$.

\section{DISCUSSION}

The results of the present study give strong support to the hypothesis that exposure to particulate air pollution increases the risk of dying from ischaemic heart disease, not only when the exposure is environmental but also when it is occupational. For cerebrovascular disease we found no clear associations but some tendencies, which is in line with the conflicting results of the studies of ambient particle exposure. The mortality risk associated with occupational exposure was most pronounced in the occupationally active age span 20-59 years.

The main strength of the present study is that it is a prospective longitudinal study of a large cohort, and that it includes information about relevant confounders such as smoking habits, body mass index and blood pressure. Furthermore, we were able to use an internal control group. This limits the influence of healthy worker selection bias.

It is probable that the workers in the control group had some particulate air pollution exposure, albeit lower than in the exposed group, because (1) there is a general dust exposure at most construction sites, so no one in the cohort is really unexposed, and (2) our exposure assessment is only taking the first recorded job title into account; the worker may later have changed occupation. This may cause underestimations of the risks. It should, however, be noted that Swedish construction workers largely remain in the same occupation within the construction industry. As both the exposed workers and those in the control group were construction workers, there is a limited difference between them regarding socioeconomic factors and lifestyle.

The JEM was based on exposure estimations from the 1970s. It originated from an extensive exposure assessment project engaging several industrial hygienists with experience from the construction industry. Hence, we regard the JEM as valid, although no formal validation had been made.

Based on our personal experience, the exposure to dust among Swedish construction workers is still rather high and similar to previous decades. This is also supported by a Swedish investigation from 2004 showing that the threshold limit values for silica dust and total dust were exceeded in $65 \%$ of the measurements. ${ }^{27}$ Hence, we think that the findings in the present study may well reflect a risk still existent in this workforce. 
The classification of smoking habits in the study was not time-dependent and neither did it differentiate between smokers with high and low daily tobacco consumption. Hence, the results for the whole group may be criticised, as the exposed group may have had different cumulative exposure to tobacco smoke-that is, different pack-years. This potential confounding should however not have influenced the results very much, because separate analyses of never-smokers only showed results similar to the whole group (though not with statistical significance). These analyses were possible because of the size of the data set.

The results from the person-years analysis and Poisson regression models were quite similar, especially regarding the category "Any occupational exposure to particulate air pollution". Regarding the four different categories the results were also similar with one exception. The increased risk for wood dust disappeared in the Poisson regression analysis. One reason could be overlapping exposures. One quarter of the wood dust exposed workers were also exposed to fumes, hence the increased risk may have been carried by the fume exposed subjects.

One weakness of the study is the lack of information about serum cholesterol levels at baseline. Cholesterol levels may differ between different exposure groups within the group of construction workers, acting as a confounder. As the data are already adjusted for hypertension, smoking and BMI, any residual confounding from cholesterol must be minimal. However, it should be stressed that the present study shows increased risks for well-known risk factors such as smoking, BMI and hypertension, indicating a consistency in the results.

Previous studies regarding mortality and ambient air pollution have suggested that the risk for both ischaemic heart disease and cerebrovascular disease is affected. ${ }^{1}$ The mechanisms are not clearly understood, but it has been suggested that particulate air pollution induces a low-grade pulmonary inflammatory response and subsequent release of pro-inflammatory cytokines. This may result in increased coagulability of the blood, triggering cardiovascular events in susceptible subjects. ${ }^{28}$ Similar mechanisms have also been proposed for occupationally exposed subjects. ${ }^{29}$ It has also been shown that tunnel workers (who are heavily exposed to inorganic dust) have increased blood concentrations of interleukin-6 and fibrinogen during their work shift. ${ }^{30}$ Interleukin-6 is released from the bronchial mucosa and stimulates the production of fibrinogen in the liver. There is also an association between respiratory symptoms and ischaemic heart disease, ${ }^{31}$ further supporting the link between airway inflammation and ischaemic heart disease.

However, an alternative hypothesis to the inflammatory/ accelerated atherosclerosis hypothesis has been suggested. There is accumulating evidence showing an association between ambient particulate air pollution and disturbances of the cardiac autonomic nervous system. ${ }^{32}$ Several groups have reported changes in heart rate or heart rate variability associated with ambient particulate air pollution. ${ }^{12-14}$ Further support for an altered cardiac function is the observation of changes in heart rate variability after occupational exposure to fine particles. ${ }^{33}$

The risks in the present study was higher in the group in working age (20-59 years), which may indicate that current exposure is more important than chronic exposure. However, other explanations are possible, such as changed dietary habits over the years. A more acute effect of exposure may be mediated through short-term effects such as disturbances in the autonomic nervous system. The impact of different time windows was analysed in a case-referent study on myocardial infarction and occupational exposures, without finding any further increased

\section{Main message}

- Occupational exposure to particulate air pollution in construction workers increases the risk for ischaemic heart disease.

\section{Policy implication}

- The exposure to particulate air pollution at workplaces should be kept as low as possible.

risks when analysing exposure close to the events. ${ }^{22}$ It has been noted that the effect size in short-term exposures or withdrawals is similar to that reported in long-term studies, hence it appears that the effects of air pollution develop and abate during rather short time periods. ${ }^{11}$ The present study gives some support to the importance of short-term effects.

Exposure to diesel exhaust was associated with an increased risk for ischaemic heart disease. This may indicate that diesel exhaust particles are more toxic than other combustion/exhaust particles. This is supported by experimental data, but evidence from epidemiological studies are lacking. ${ }^{34} 35$

In conclusion, occupational exposure to dust, gases and fumes increased the risk for ischaemic heart disease, but there was no clearly increased risk for cerebrovascular disease. The results underscore the need to keep exposure to particulate air pollution in workplaces as low as possible.

\section{ACKNOWLEDGEMENTS}

This study was supported by the Swedish Council for working life and social research.

\section{Authors' affiliations}

K Torén, Department of Occupational and Environmental Medicine, Sahlgrenska University Hospital, Göteborg, Sweden

T Nilsson, Department of Occupational and Environmental Medicine, Sundsvall Hospital, Sundsvall, Sweden

I A Bergdahl, B Järvholm, Occupational Medicine, Department of Clinical Medicine and Public Health, Umeå University, Umeå, Sweden

Competing interests: None declared.

\section{REFERENCES}

1 Hoek G, Brunekreef B, Fischer $\mathrm{P}$, et al. The association between air pollution and heart failure, arrhythmia, embolism, thrombosis and other cardiovascular causes of death in a times series study. Epidemiology 2001;12:355-7.

2 Dockery DW, Pope CA III, Xu X, et al. An association between air pollution and mortality in six US cities. N Engl J Med 1993;329:1753-9.

3 Pope CA, Thun MJ, Namnboodri MM, et al. Particulate air pollution as a predictor of mortality in a prospective study of U.S. adults. Am J Respir Crit Care Med 1995;151:669-74.

4 Samet JM, Dominici F, Curriero FC, et al. Fine particulate air pollution and mortality in 20 U.S. cities. N Engl J Med 2000;343:1742-9.

5 Pope CA III, Burnett RT, Thun MJ, et al. Lung cancer, cardiopulmonary mortality and long-term exposure to fine particulate air pollution. JAMA 2002;287:1132-41

6 Laden F, Schwartz J, Speizer FE, et al. Reduction in fine particulate air pollution and mortality. Extended follow-up of the Harward six cities study. Am J Crit Care Med 2006; 173:667-72.

7 Hong YC, Lee JT, Kim H, et al. Air pollution: A new risk factor in ischemic stroke mortality. Stroke 2002;33:2165-9.

8 Maheswaran R, Haining RP, Brindley $P$, et al. Outdoor air pollution and stroke in Sheffield, United Kingdom. A small-area level geographical study. Stroke 2005;36:239-43.

9 Pope CA III, Burnett RT, Thurston GD, et al. Cardiovascular mortality and longterm exposure to particulate air pollution. Epidemiological evidence of general pathophysiological pathways of disease. Circulation 2004;109:71-7.

10 Seaton A, Soutar A, Crawford V, et al. Particulate air pollution and the blood. Thorax 1999;54:1027-32. 
11 Bhatnagar A. Environmental cardiology studying mechanistic links between pollution and heart disease. Circ Res 2006;99:692-705.

12 Gold DR, Litonjua A, Schwartz J, et al. Ambient pollution and heart rate variability. Circulation 2000;101:1267-73.

13 Liao D, Creason J, Shy C, et al. Daily variation of particulate air pollution and poor cardiac autonomic control in the elderly. Environ Health Persp 1999; 107:521-5.

14 Riediker M, Cascio WE, Griggs TR, et al. Particulate matter exposure in cars is associated with cardiovascular effects in healthy young men. Am J Respir Crit Care Med 2004; 169:934-40

15 Pekkanen J, Peters A, Hoek G, et al. Particulate air pollution and risk of STsegment depression during repeated submaximal exercise among subjects with coronary heart disease: the Exposure and Risk assessment for fine and ultrafine particles in ambient air (ULTRA) study. Circulation 2002;106:933-8.

16 Peters A, Liu E, Verrier RL, et al. Air pollution and the incidence of cardiac arrythmia. Epidemiology 2000;11:11-17.

17 Stone DH, Godleski JJ. First step toward understanding the pathophysiological link between air pollution and cardiac mortality. Am Heart J 1999;138:804-7.

18 Hammar $\mathbf{N}$, Alfredsson L, Smedberg $M$, et al. Large differences in the incidence of myocardial infarction among occupational groups. Scand J Work Environ Health 1992;18:178-85.

19 Wyndham CH, Bezuidenhout BN, Greenacre MJ, et al. Mortality of middle-aged white South African gold miners. Br J Ind Med 1986;43:677-84.

20 Hansen ES. Mortality from cancer and ischemic heart disease in Danish chimney sweeps: a five-year follow-up. Am J Epidemiol 1983;117:160-4.

21 Sali D, Bofetta P, Andersen A, et al. Non-neoplastic mortality of European workers who produce man made vitreous fibres. Occup Env Med 1999;56:612-17

22 Gustavsson P, Plato N, Hallqvist J, et al. A population-based case-referent study of myocardial infarction and occupational exposure to motor exhaust, other combustion products, organic solvents, lead, and dynamite. Epidemiology $2001 ; 12: 222-8$.

23 Chow WH, Gridley G, Fraumeini J, et al. Obestity, hypertension and the risk for kidney cancer among men. N Engl J Med 2000;343:1305-11.

24 Bergdahl IA, Torén K, Eriksson K, et al. Increased mortality in COPD among construction workers exposed to inorganic dust. Eur Respir J 2004;23:402-6.

25 Berry G. The analysis of mortality by the subject-years method. Biometrics 1983;39:173-84.

26 Aitkin M. Anderson D, Francis B, et al. Statistical modelling in GLIM. Oxford: Clarendon Press, 1990.

27 Norén JO. Byggdamm vid ROT-arbeten. Rapport 2005: 2, Arbetsmiljöverket, Sweden [In Swedish].

28 Townsend JN. The way to dusty death. Thorax 2005;60:441-2.

29 Siögren B. Occupational exposure to air pollutants, inflammation and ischemic heart disease. Scand J Work Environ Health 2004;30:421-3.

30 Hilt B, Qvenild T, Holme J, et al. Increase in interleukin-6 and fibrinogen after exposure to dust in tunnel construction workers. Occup Environ Med 2002;59:9-12.

31 Jousilahti $\mathbf{P}$, Vartiainen E, Tuomilehto J, et al. Symptoms of chronic bronchitis and the risk of coronary disease. Lancet 1996;348:567-72.

32 Pope CA III, Verrier RL, Lovett EG, et al. Heart rate variability associated with particulate air pollution. Am Heart J 1999;138:890-9.

33 Magari SR, Hauser R, Schwartz J, et al. Association of heart rate variability with occupational and environmental exposure to particulate air pollution. Circulation $2001 ; 104: 986-91$.

34 Mills NL, Törnqvist H, Robinson SD, et al. Diesel exhaust inhalation causes vascular dysfunction and impaired endogenous fibrinolysis. Circulation 2005; 1 12:3930-6.

35 Nemmar A, Hoet PH, Dinsdale D, et al. Diesel exhaust particles in lung acutely enhance experimental peripheral thrombosis. Circulation 2003;107:1202-8.

\section{Access the latest content chosen by our Editors}

BMJ Journals editors select an article from each issue to be made free online immediately on publication. Other material is free after 12 months to non-subscribers. Access the Editor's Choice from the home page - or expand your horizons and see what the other BMJ Journals editors have chosen by following the links on any BMJ Journal home page. 